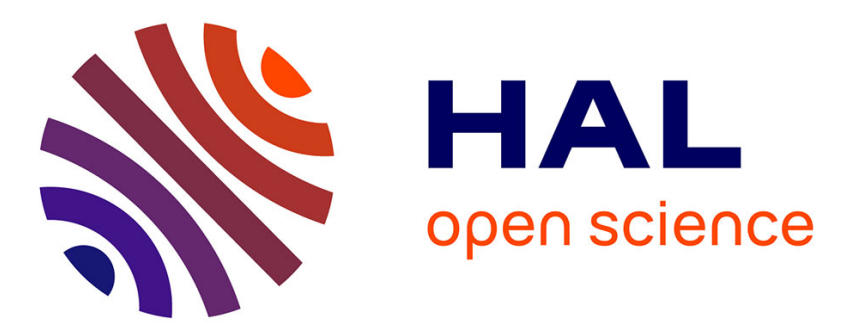

\title{
Analysis of transient vibrations on complex targets representing elementary configurations of GOCE satellite
}

D. Pavarin, A. Francesconi, R. Destefanis, M. Faraud, M. Lambert, A. Bettella, C. Giacomuzzo, P.C. Marucchi-Chierro, R. Ullio, F. Angrilli

\section{To cite this version:}

D. Pavarin, A. Francesconi, R. Destefanis, M. Faraud, M. Lambert, et al.. Analysis of transient vibrations on complex targets representing elementary configurations of GOCE satellite. International Journal of Impact Engineering, 2008, 35 (12), pp.1709. 10.1016/j.ijimpeng.2008.07.014 hal00542561

\section{HAL Id: hal-00542561 \\ https://hal.science/hal-00542561}

Submitted on 3 Dec 2010

HAL is a multi-disciplinary open access archive for the deposit and dissemination of scientific research documents, whether they are published or not. The documents may come from teaching and research institutions in France or abroad, or from public or private research centers.
L'archive ouverte pluridisciplinaire HAL, est destinée au dépôt et à la diffusion de documents scientifiques de niveau recherche, publiés ou non, émanant des établissements d'enseignement et de recherche français ou étrangers, des laboratoires publics ou privés. 


\section{Accepted Manuscript}

Title: Analysis of transient vibrations on complex targets representing elementary configurations of GOCE satellite

Authors: D. Pavarin, A. Francesconi, R. Destefanis, M. Faraud, M.

Lambert, A. Bettella, C. Giacomuzzo, P.C. Marucchi-Chierro, R. Ullio, F.

Angrilli

PII: $\quad$ S0734-743X(08)00160-7

DOI: $\quad$ 10.1016/j.ijimpeng.2008.07.014

Reference: IE 1642

To appear in: International Journal of Impact Engineering

Received Date:

Revised Date:

Accepted Date:

Please cite this article as: Pavarin D, Francesconi A, Destefanis R, Faraud M, Lambert M, Bettella A, Giacomuzzo C, Marucchi-Chierro PC, Ullio R, Angrilli F. Analysis of transient vibrations on complex targets representing elementary configurations of GOCE satellite, International Journal of Impact Engineering (2008), doi: 10.1016/j.ijimpeng.2008.07.014

This is a PDF file of an unedited manuscript that has been accepted for publication. As a service to our customers we are providing this early version of the manuscript. The manuscript will undergo copyediting, typesetting, and review of the resulting proof before it is published in its final form. Please note that during the production process errors may be discovered which could affect the content, and all legal disclaimers that apply to the journal pertain. 


\title{
Analysis of transient vibrations on complex targets representing elementary configurations of GOCE satellite
}

\author{
D.Pavarin $^{1 *}$, A.Francesconi ${ }^{1}$, R.Destefanis ${ }^{3}$, M.Faraud ${ }^{3}$, M.Lambert ${ }^{2}$, A.Bettella ${ }^{1}$, \\ C.Giacomuzzo ${ }^{1}$, P.C. Marucchi-Chierro ${ }^{3}$, R.Ullio ${ }^{3}$, F.Angrilli ${ }^{1}$ \\ ${ }^{(1)}$ CISAS University of Padova, Via Venezia 15, 35131 Padova, Italy. \\ (2) ESA ESTEC, Postbus 299, NL-2200AG Noordwik, The Netherlands. \\ (3) Thales Alenia Space Italia s.p.a, Turin, Italy. Torino Str. Antica di Collegno 25310146 Torino, Italy.
}

\begin{abstract}
In order to analyze the propagation of shocks due to hypervelocity impact of micrometeoroids and space debris on spacecrafts, it was necessary to analyze the high-frequency shock-propagation-dynamic on complex structures representative of real spacecraft structure. Object of this research is the GOCE satellite due to its highly accurate accelerometer very sensitive to the micro-vibration environment. After a detailed analysis of the most-probable shock-propagation-path within the satellite, several representative-targets have been designed. Then an extensive test campaign has been conducted on these targets exploring a wide range of impact conditions. As a result, a database was established which correlates the impact conditions in the experimental range (0.6 to $2.3 \mathrm{~mm}$ projectiles at 2.5 to $5 \mathrm{~km} / \mathrm{s}$ ) with the shock spectra on selected locations on various types of structural models. The behavior of structural joints was also analyzed under shock conditions that are not normally reproduced by pyroshock testing. The data base represent a fundamental tool in order to validate the numerical analysis that will be used to asses the vibration environment, due to in-orbit micrometeoroids and space debris at the accelerometer location. This paper present the test procedure applied and the general results achieved.
\end{abstract}

Keywords: Hypervelocity Impact (HVI); Micrometeoroid and Orbital Debris (MMOD); spacecraft vibration environment, spacecraft disturbances, gradiometer, hypervelocity testing.

\section{Introduction}

Space debris and meteoroids are a well known source of possible damage for satellites. Nevertheless, among the potential consequences of hypervelocity impacts (HVI) on spacecrafts, the external wall penetration is the only effect that was subjected to extensive investigation to date. Some experiments recognized that the vibration environment induced by HVI could be close to that generated by pyroshock devices [1],[2], being therefore a real threat for components and instrumentation.

\footnotetext{
*Corresponding author. Tel.: +390498276855 Fax: +390498276855, E-mail address: daniele.pavarin@unipd.it
} 
Moreover, for those satellites including equipment very sensitive to small accelerations, it appears worthy to define the impact damage as a range of local perturbations in the vicinity of sensitive instruments. To date, the HVI-induced vibration environment was studied by means of acoustic emission by Prosser [3],[4], but its full characterization as suggested for example by NASA [5] have not been performed yet. In this framework, it was recognized the need of getting a collection of impact test data addressing thoroughly the shock spectrum inside spacecrafts resulting from space debris impacts on the external walls of the body, with the final goal of defining a general approach for characterizing and predicting the vibration environment around selected components, with its dependence from impact conditions (i.e. micrometeoroid or orbital debris mass, impact speed, impact angle). The maximum frequency requirement for this study was set by ESA at $10 \mathrm{kHz}$.

To do that, an extensive HVI impact test campaign was conducted at CISAS Light Gas Gun Facility, to collect the required data on spacecraft-representative structural models. For this study, aluminium spheres ( 0.6 to $2.3 \mathrm{~mm}$ diameter) were launched at velocities between 2 and $5 \mathrm{~km} / \mathrm{s}$. Targets were representative of the GOCE satellite. GOCE was selected as reference case because of its payload (gradiometer) sensitive to even very small external disturbances [6],[7]. Hence, starting from the GOCE structural configuration, various load paths were identified to define different simplified structural models. This paper presents results of tests conducted on target representing the GOCE flight configuration, in order to characterize response of joints to shock generated by hypervelocity impact. This work is a fundamental step in order to asses the vibration environment induced by the impact of meteoroids and space debris on sensitive locations of GOCE.

\section{Review of GOCE}

The reference spacecraft selected for the study is the Gravity Field and Steady-State Ocean Circulation Explorer (GOCE) satellite. The payload of GOCE is a gradiometer designed to provide global and regional models of the Earth's gravity field and of the geoid with high spatial resolution and accuracy. The GOCE orbit is sun-synchronous (96.5 degrees of inclination), circular, at very low altitude (between 240 and $250 \mathrm{~km}$ ). The mission is scheduled to start before 2008. .

This satellite is sensitive to very low acceleration $\left(10^{-12} \mathrm{~m} / \mathrm{s}^{2}\right)$ and has to satisfy severe microvibration system requirements. Perturbations due to micro-vibrations caused by various natural events, like atmospheric drag, Sun flux, MMOD impacts etc. have not to hamper the achievement of the required acceleration measurements.

\subsection{GOCE structural configuration}

A GOCE scheme is presented in Fig. 1. The satellite consists of an octagon prismatic shell, about 5 $\mathrm{m}$ long and with a transversal cross section of about $1.1 \mathrm{~m}^{2}$. The octagon is composed of a single half shell of $180^{\circ}$ and of eight additional panels that are part of the backside shell for integration reasons. Once in orbit, the half shell is pointing towards the sun, while the remaining panels are in shade. All electronics units are placed on seven internal platforms named floors. The octagonal shell is a sandwich structure with CFRP face-sheets $2 \mathrm{~mm}$ thick and Al H/C core $11 \mathrm{~mm}$ high. Five floors are both with face-sheets and aluminum H/C, while two floors are with CFRP face-sheets and aluminum H/C. The octagonal cylinder detachable panels ( 


\section{Pavarin, et al / International Journal of Impact Engineering}
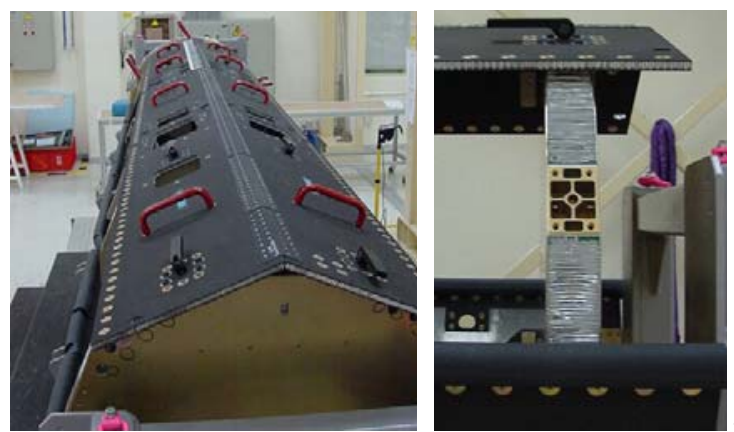

Fig. 2, left) are connected together by CFRP lashings, through hole inserts and screws.

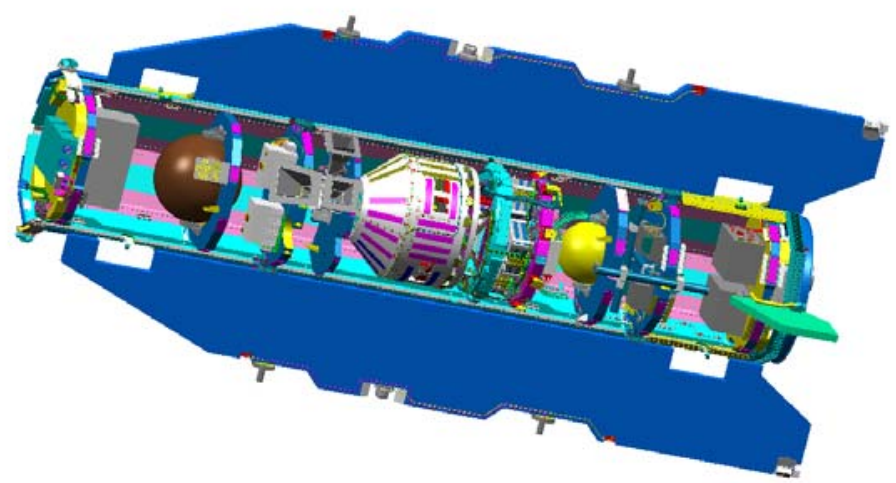

Fig. 1. Actual design solution of the GOCE satellite.
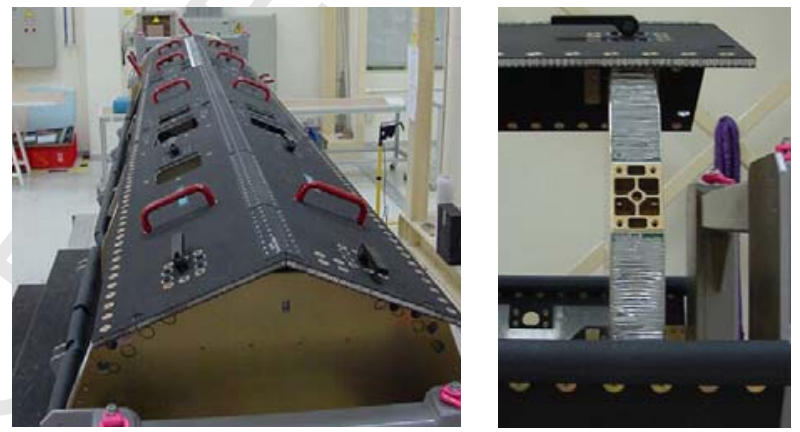

Fig. 2. GOCE Engineering Model: octagonal cylinder (left), junction between floor and side panel (right).

The floors are attached to the octagonal cylinder by embedded metallic brackets, each of them providing four threaded holes to fix the floors to the side panels of the cylinder ( 
Pavarin, et al / International Journal of Impact Engineering
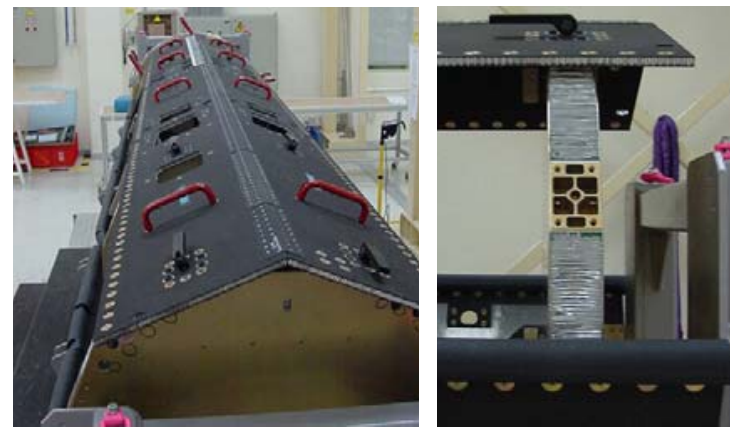

Fig. 2, right).

\subsection{Definition of the impact conditions for laboratory experiments}

Impact conditions for laboratory experiments were selected to obtain useful results not only for GOCE, but even for other satellites. Therefore, it was decided to consider MMOD having mass capable to induce significant disturbances or damages onto a generic spacecraft. Hence, the range of variation for projectiles size was selected to be centered around $1 \mathrm{~mm}$ diameter. This choice is justified mainly by the following considerations.

Firstly, the mean time between impacts for particles with diameter between $0.1 \mathrm{~mm}$ and $1 \mathrm{~mm}$ is around 160 days [6]. Secondly, the ballistic limit of GOCE and of many other satellites structures was estimated to be reached with aluminum projectiles with diameters roughly about $1 \mathrm{~mm}$ at $5 \mathrm{~km} / \mathrm{s}$. This allows to put the experimental range across the non-penetration/penetration threshold, with the consequent opportunity of investigating the disturbance propagation in the two distinct impact regimes.

Finally, a projectile diameter range centered on $1 \mathrm{~mm}$ is very well suited for the experimental capabilities of the CISAS Light-Gas Gun Facility, which is able to launch 0.6 to $2.9 \mathrm{~mm}$ aluminum spheres up to $5.6 \mathrm{~km} / \mathrm{s}$.

\section{Impact Testing}

\subsection{Target configurations}

Complex target have been designed starting from the analysis of the GOCE structural configuration and the calculations of the MMOD flux on the spacecraft. These inputs allowed the identification of the most significant load paths along the vehicle ( 


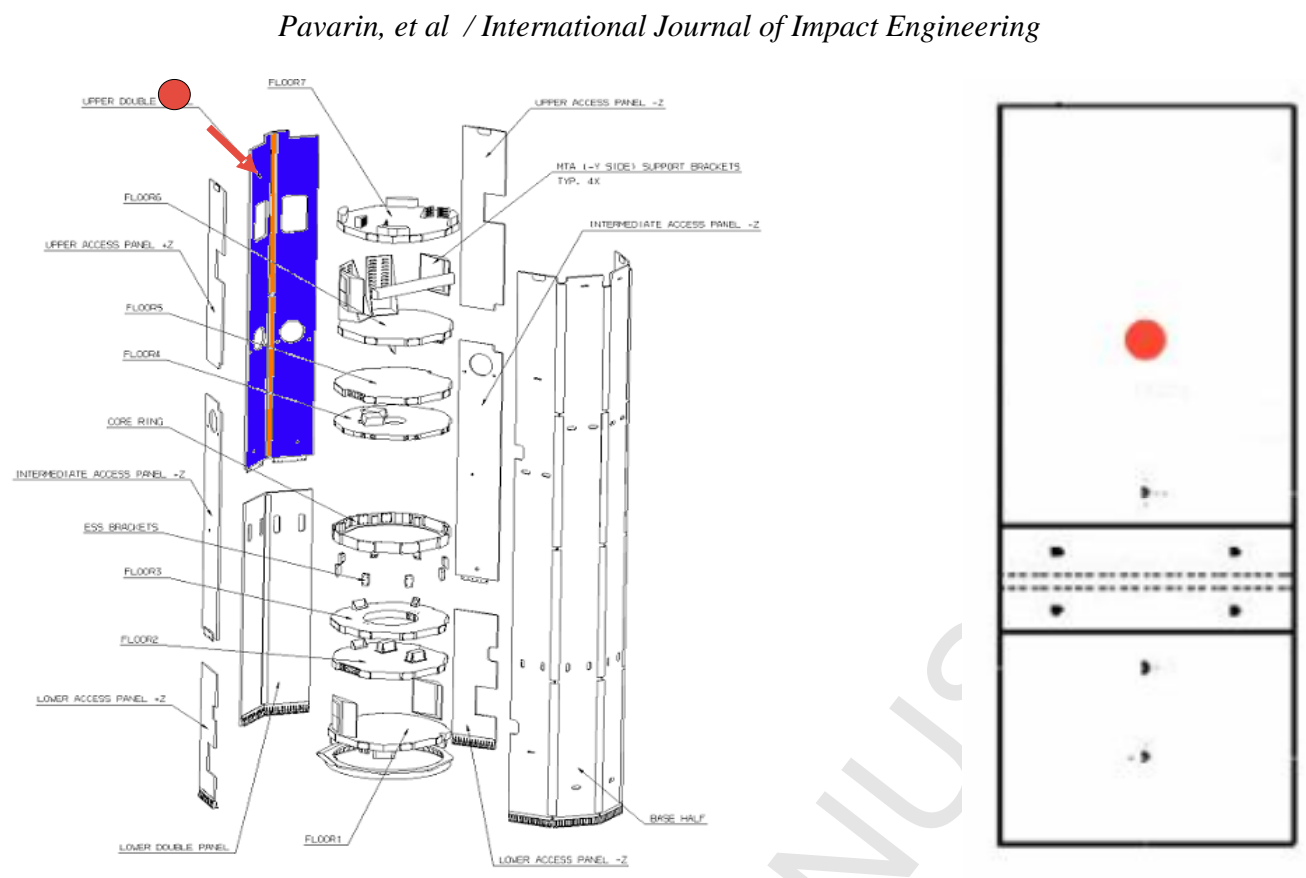

Fig. 3 to
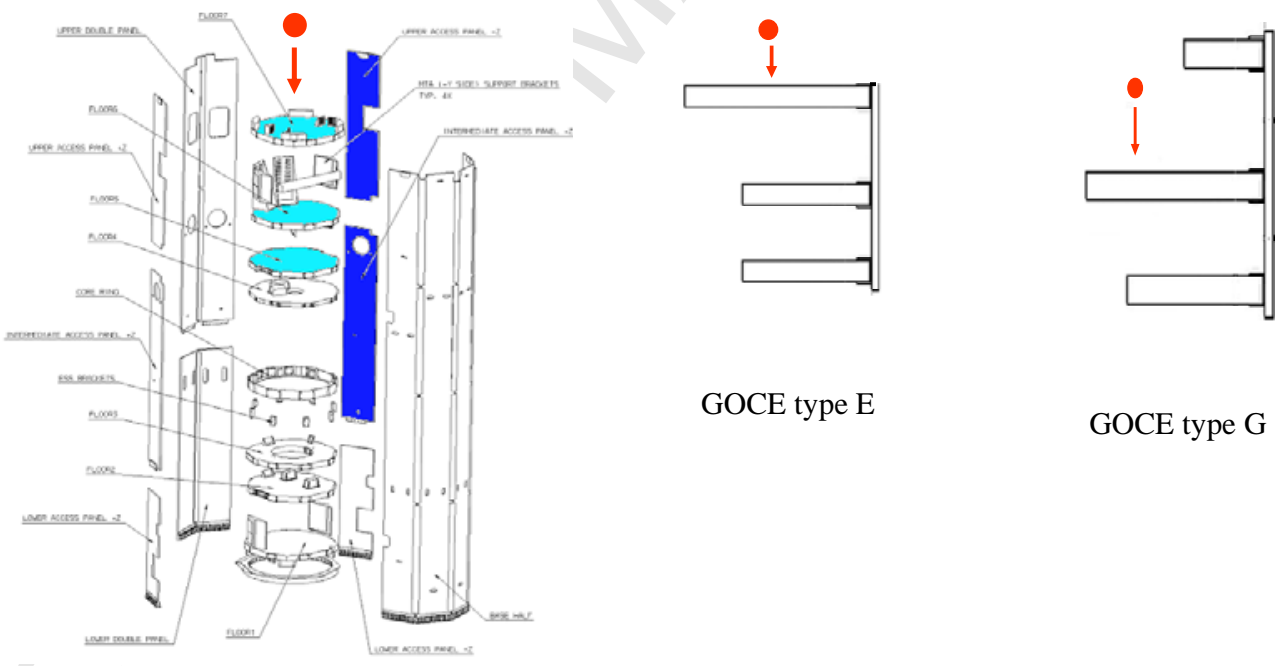

GOCE type E

GOCE type G

Fig. 6). Complex target have been built assembling sandwich panels described in Table 1 . In the GOCE C target model (Fig. 3), the two jointed panels are sandwiches with CFRP face-sheets (Table 1).

Table 1. Simplified Targets

\begin{tabular}{cccc}
\hline Target type & Face-sheet material & Core material & Size $[\mathrm{mm}]$ \\
\hline Sandwich panel & $\mathrm{Al} 2024 \mathrm{~T} 81$ & $\mathrm{Al}$ alloy & 400x400x52.8 \\
\hline
\end{tabular}


Pavarin, et al / International Journal of Impact Engineering

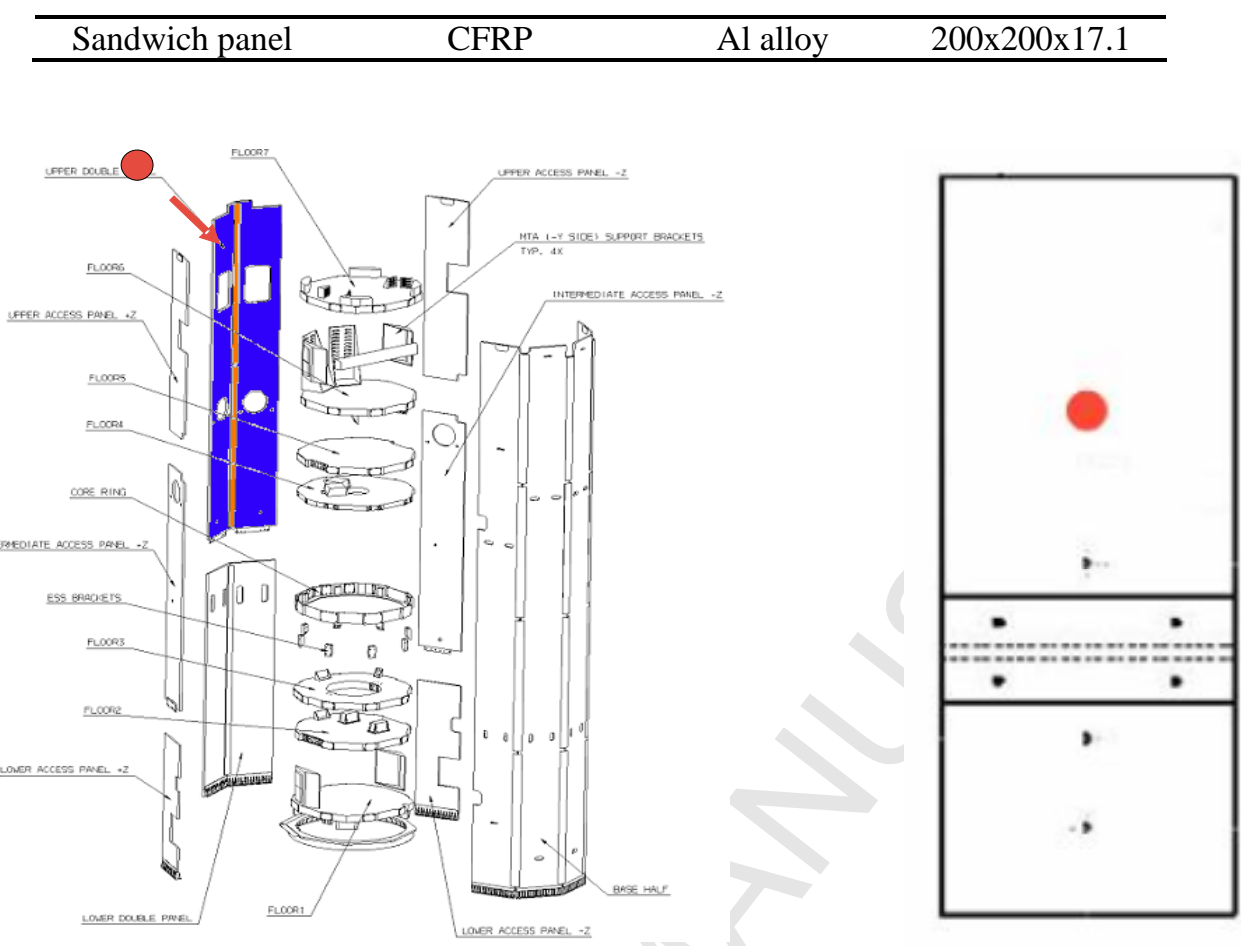

Fig. 3. GOCE C target model
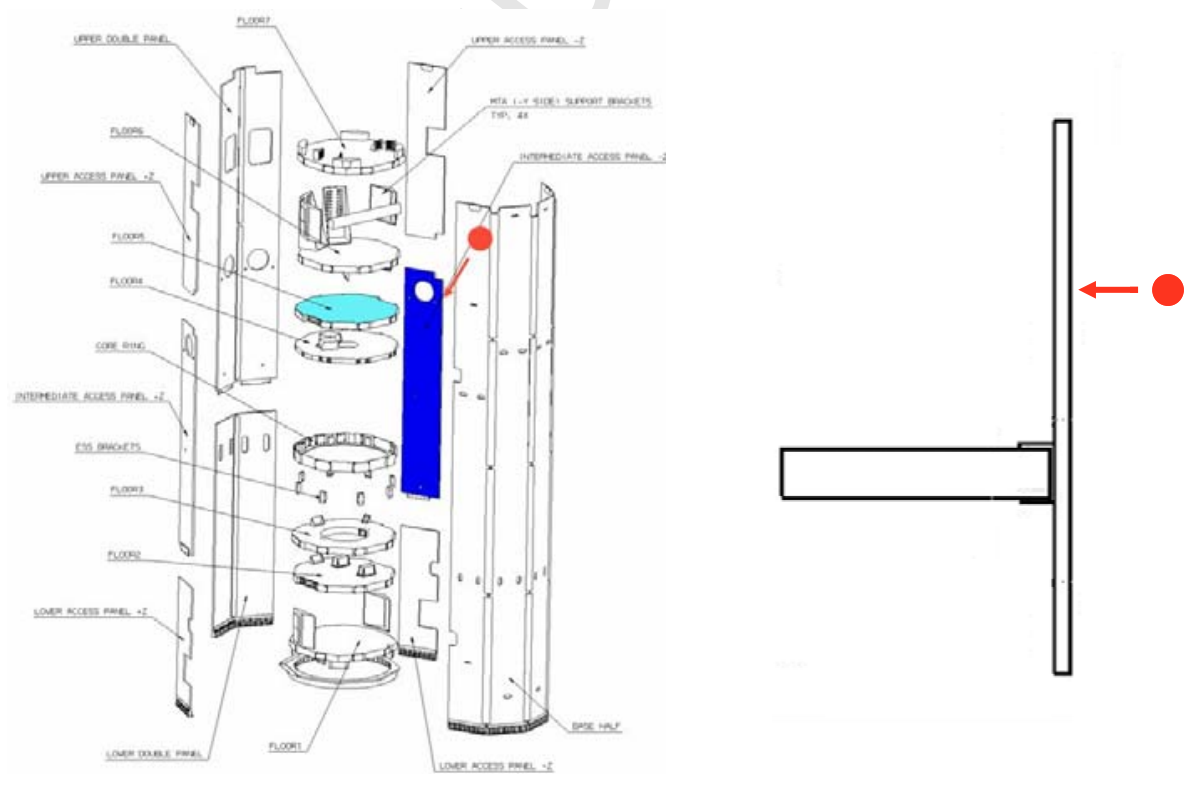
Pavarin, et al / International Journal of Impact Engineering

Fig. 4. GOCE D1 target model

In the GOCE D1 target-model (Fig. 4), the floor is a sandwich panel with aluminum face-sheets and the impacted plate is a sandwich panel with CFRP face-sheets (Table 1).
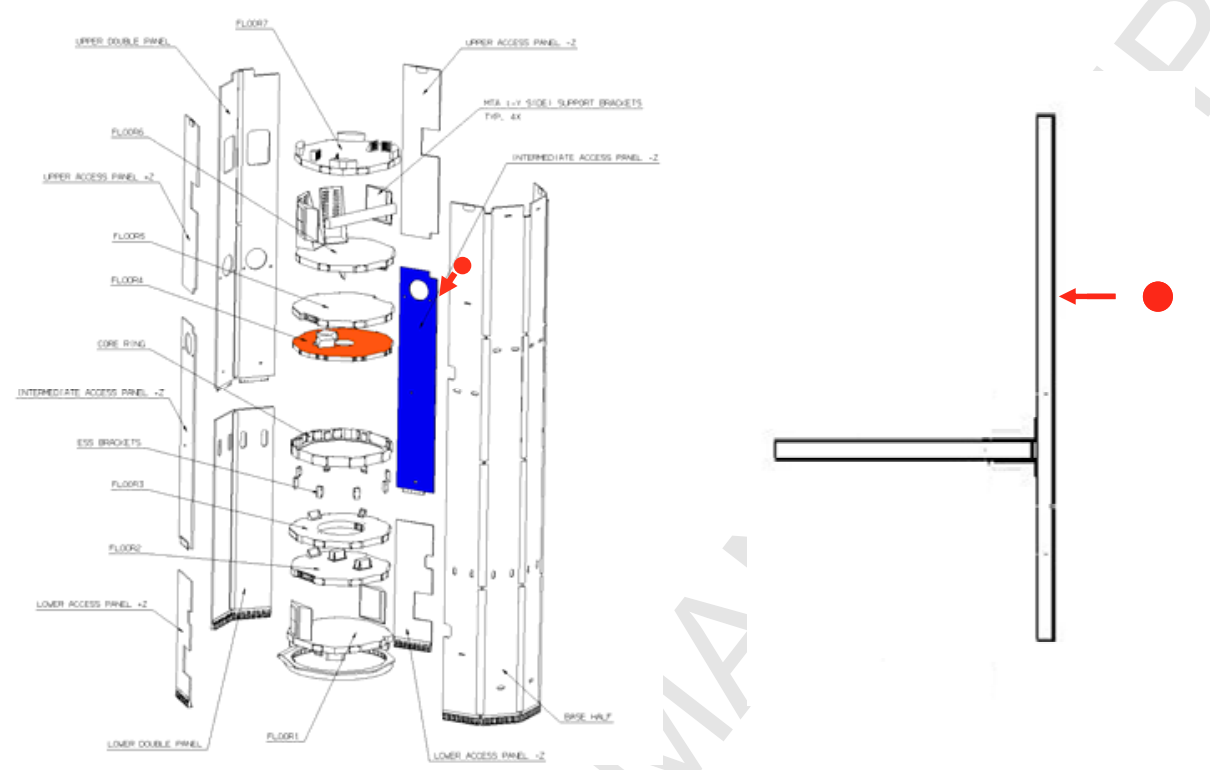

Fig. 5. GOCE D2 target model

In the GOCE D2 target-model (Fig. 5), both the floor and the impacted panel are sandwich panels with CFRP face-sheets (Table 1). 

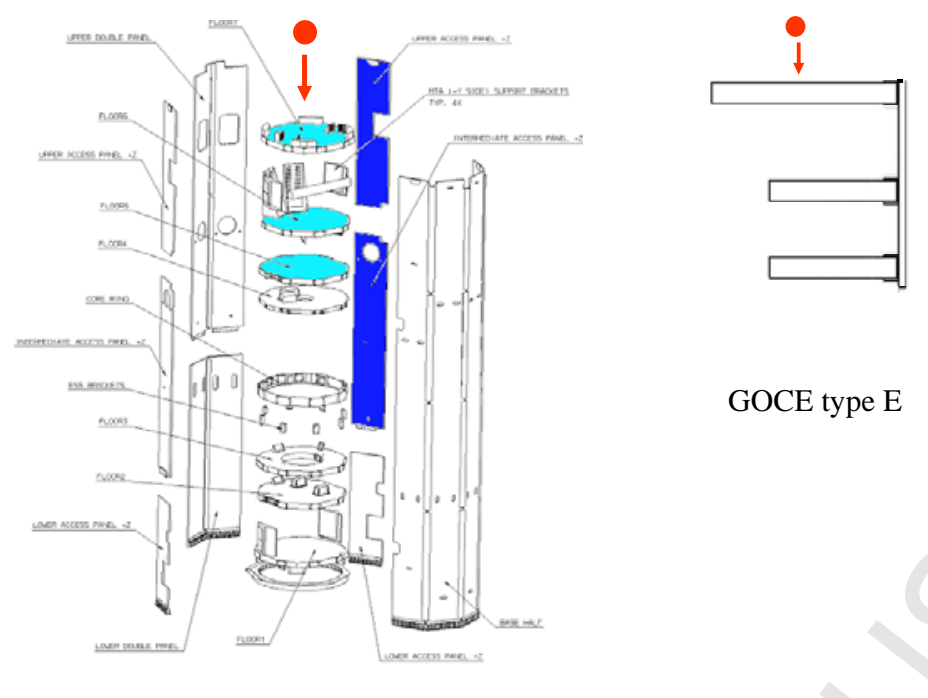

GOCE type E

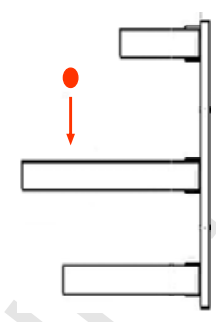

GOCE type G

Fig. 6. GOCE E and G target models

In the GOCE E and G target-model, the floors are sandwich panels with aluminum face-sheets. The connecting plate (vertical in the figure) is a sandwich panel with CFRP face-sheets (Table 1). Even though target $G$ is not representative of a real situation, it was conceived to study the disturbances propagating from an impacted plate jointed in the middle of the octagon cylinder, instead at its edge.

\subsection{Experimental setup and instrumentation}

During HVI experiments, the Light-Gas Gun was used to launch saboted projectiles into a flight chamber, in which aerodynamic sabot separation occurs (the pressure in the impact chamber was 5000 $\mathrm{Pa}$ ). The flight chamber is connected to the impact chamber holding the target. Targets were mounted through elastic suspension systems based on springs and dampers. This allowed the reduction of the dynamic coupling between the targets and the impact chamber itself. To reduce acoustic disturbances onto the targets due to propellant expansion and the residual pressure in the vacuum chamber (5000 $\mathrm{Pa}$ ) necessary to allow for sabot separation, the inner walls of the flight chamber were covered by soft absorbing material and diaphragms with calibrated holes for the projectile passage were also used. Instrumentation for disturbances measurement was based upon accelerometers (Table 2), whose dynamic range and bandwidth were selected depending on the target type (Simplified or Complex), the distance from the impact point and the position with respect of joints.

A maximum of 30 accelerometers were contemporarily used on some of the Complex Targets. Even a laser velocimeter (Polytec OFV-501, bandwidth at $-1 \mathrm{~dB} 150 \mathrm{kHz}$ ) was used for point measurements of targets acceleration, velocity and displacement. Accelerometers were attached to support-cubes in a tri axial configuration to measure directly contemporarily out-of-plane and in-plane accelerations. 
Pavarin, et al / International Journal of Impact Engineering

Table 2. Accelerometers used within the study

\begin{tabular}{cccc}
\hline Model & Output & Range $\left[\mathrm{ms}^{-2}\right]$ & $\begin{array}{c}\text { Bandwidth }[\mathrm{kHz}] \\
\text { And related uncertainty range }\end{array}$ \\
\hline Endevco 7270-200k & Voltage & $1 \mathrm{e} 3-2 \mathrm{e} 6$ & $200( \pm 1 \mathrm{~dB})$ \\
Bruel\&Kjaer 4374 & Charge & $1 \mathrm{e}-5-2 \mathrm{e} 5$ & $26( \pm 1 \mathrm{~dB})$ \\
PCB 352B01 & Voltage & $5 \mathrm{e} 2-5 \mathrm{e} 4$ & $20( \pm 10 \%)$ \\
PCB-350B03 & Voltage & $<1 \mathrm{e} 5$ & $10( \pm 1 \mathrm{~dB})$ \\
PCB-357B11 & Charge & $<2.3 \mathrm{e} 4$ & $16( \pm 10 \%)$ \\
PCB-352C22 & Voltage & $<5 \mathrm{e} 3$ & $13( \pm 10 \%)$ \\
\hline
\end{tabular}

A summary of signal conditioning systems and data acquisition systems is presented in Table 3 and

\begin{tabular}{cccc}
\hline Model & Type & Channels & Bandwidth [kHz] \\
\hline Endevco 136 & Voltage & $3 \times 2$ & $100( \pm 3 \mathrm{~dB})$ \\
Bruel\&Kjaer 2694 & Voltage & 16 & $50( \pm 1 \mathrm{~dB})$ \\
Dewetron DAQ- & Voltage / Charge & 12 & $50( \pm 3 \mathrm{~dB})$ \\
charge & Voltage /Charge & 20 & $200( \pm 1 \mathrm{~dB})$ \\
CISAS Custom & V
\end{tabular}

Table 4 respectively. To manage the data acquisition systems and to perform post-processing analysis on the acquired signals, a specific data acquisition and analysis software (ASAS) was developed by CISAS. After each test, it performs the following operations: signals validity checks (spikes, saturation, zero-shifts, signal to noise ratio, velocity validation, SRS validation), filtering, computation of Fast Fourier Transform (FFT) and Shock Response Spectrum (SRS) [8]-[11], numerical integration, evaluation of transfer functions between selected channels and generation of output files of various formats. In particular, special attention was given to raw data validation, to ensure the requested reliability of the following analyses.

Table 3. Signal conditioning systems used within the study

\begin{tabular}{cccc}
\hline Model & Type & Channels & Bandwidth [kHz] \\
\hline Endevco 136 & Voltage & $3 \mathrm{x} 2$ & $100( \pm 3 \mathrm{~dB})$ \\
Bruel\&Kjaer 2694 & Voltage & 16 & $50( \pm 1 \mathrm{~dB})$ \\
Dewetron DAQ- & Voltage / Charge & 12 & $50( \pm 3 \mathrm{~dB})$ \\
charge & Voltage /Charge & 20 & $200( \pm 1 \mathrm{~dB})$ \\
CISAS Custom & Vo
\end{tabular}

Table 4. Data acquisition systems used within the study

\begin{tabular}{cccc}
\hline Model & Type & Channels & Sampling rate $[\mathrm{kS} / \mathrm{s}]$ \\
\hline Yokogawa 1540 & Scope & $4 \mathrm{x} 2$ & 200000 \\
Lecroy LT264M & Scope & 4 & 1000000 \\
Yokogawa WE7275 & PC based & 6 & 1000 \\
Yokogawa WE7272 & PC based & 32 & 100 \\
\hline
\end{tabular}

\subsubsection{Analysis of Target E}

As an example of the analysis conducted on complex target, part of the investigations conducted of target type E (see Fig. 7), are reported in the following. Results are provided only for HVI tests even if 
several hammer tests have also been conducted. The post-processing of the SRS functions coming from the GOCE Configuration E test campaign has been also devoted to the extraction of the experimental attenuation of disturbances due to effects of junction and distance from the impact site.

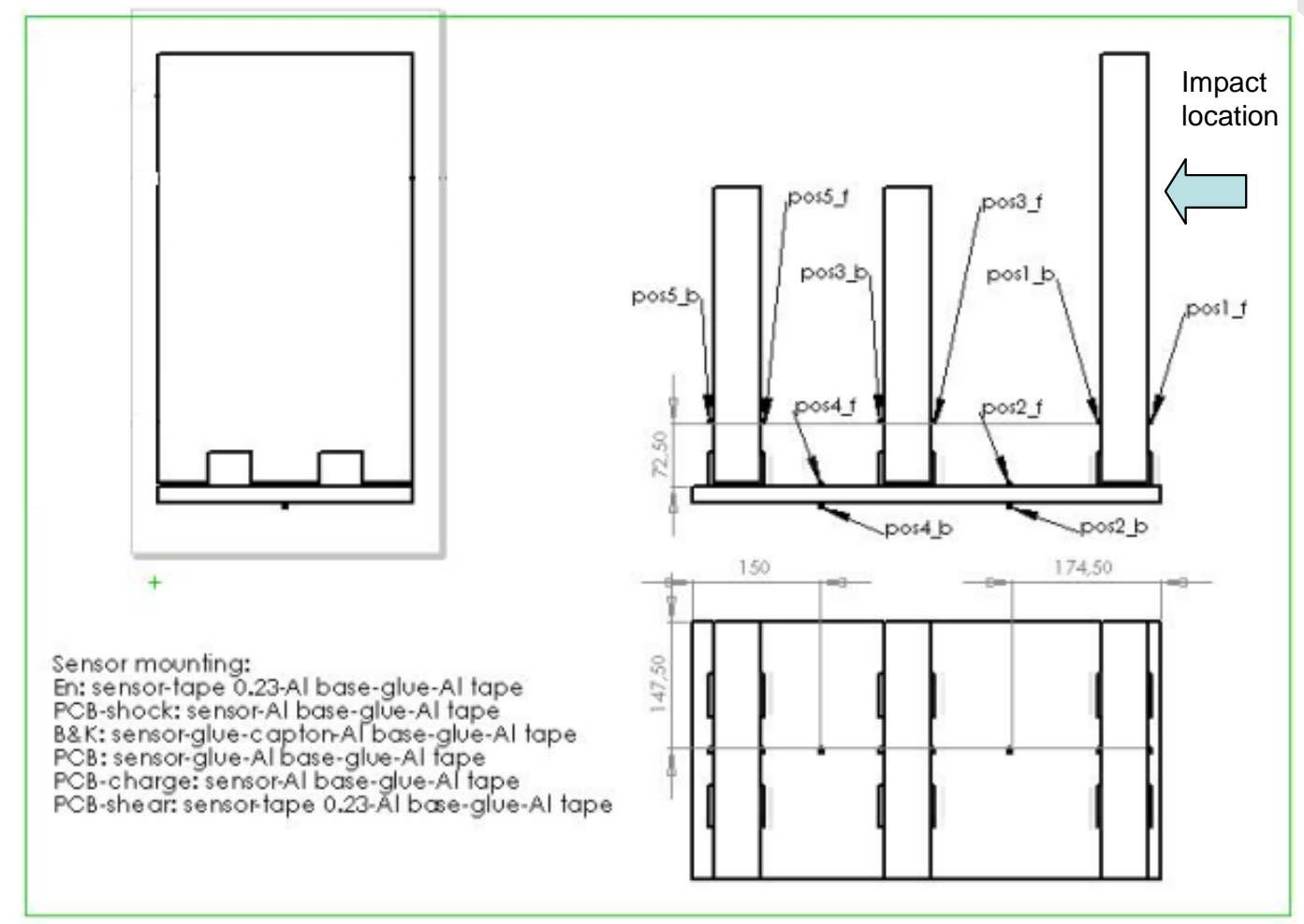

Fig. 7 Target E with accelerometer location, for each location accelerometer have been placed on three axis.

As a first step it was derived, on each accelerometer location, the SRS function that envelope the six experimental SRS functions measured at each accelerometer location:

(1) the three SRS on the front face along the

- X Axis (in plane direction)

- Y Axis (out of plane direction)

- Z Axis (in plane shear direction), and

(2) the three SRS on the back face along the

- X Axis (in plane direction)

- Y Axis (out of plane direction)

- Z Axis (in plane shear direction)

Then, the results in terms of SRS ratio have been extracted as follow:

- Between the Impacted panel (i.e. accelerometer location “pos1”) and the Connected panels (i.e. accelerometer locations "pos3" and "pos5") to evaluate the global effects of two and three junctions on disturbances in the aluminum vertical panels, located at different distances from the impact point. 
- Between the Impacted panel (i.e. accelerometer location "pos1”) and the Connected panel (i.e. accelerometer locations "pos2" and "pos4") to evaluate the influence of one and two junctions on disturbances in the CFRP sandwich panel at different distances from the impact point.

- In order to obtain the SRS attenuation functions (calculated as ratio between different SRS as explained above) representative in different shot parameter conditions (i.e. at different projectile speed, mass and type of impact) the shots reported in Table 5 and in Table 6 have been selected.

Table 5. Penetrating selected shots

\begin{tabular}{|l|c|c|c|c|c|l|}
\hline TITLE & SHOT IDN & ESA Code & Dp (mm) & Vp (km/s) & P / NP & Note(s) \\
\hline Calibration vs. Mass \& Velocity & 7819 & TS-312/6 & 1.5 & 4.1 & P & --- \\
Data Scattering & 7850 & TS-315/2 & 1.5 & 5.0 & P & -- \\
Calibration vs. Mass \& Velocity & 7816 & TS-312/8 & 2.3 & 4.3 & P & -- \\
Calibration vs. Mass \& Velocity & 7810 & TS-312/4 & 2.3 & 5.1 & P & --- \\
\hline
\end{tabular}

Table 6 Non-Penetrating selected shots.

\begin{tabular}{|l|c|c|c|c|c|l|}
\hline TITLE & SHOT IDN & ESA Code & Dp (mm) & Vp (km/s) & P / NP & Note(s) \\
\hline Influence of Projectile Mass & 7840 & TS-314/2 & 0.6 & 5.0 & NP & --- \\
Influence of Impact Velocity & 7829 & TS-313/2 & 1.0 & 3.4 & NP & --- \\
Calibration vs. Mass \& Velocity & 7831 & TS-312/1 & 1.0 & 4.9 & NP & --- \\
\hline
\end{tabular}

Two different figures have been carried out, for each examined shot, to show the effects of the junctions and of the distance on the SRS attenuation functions.
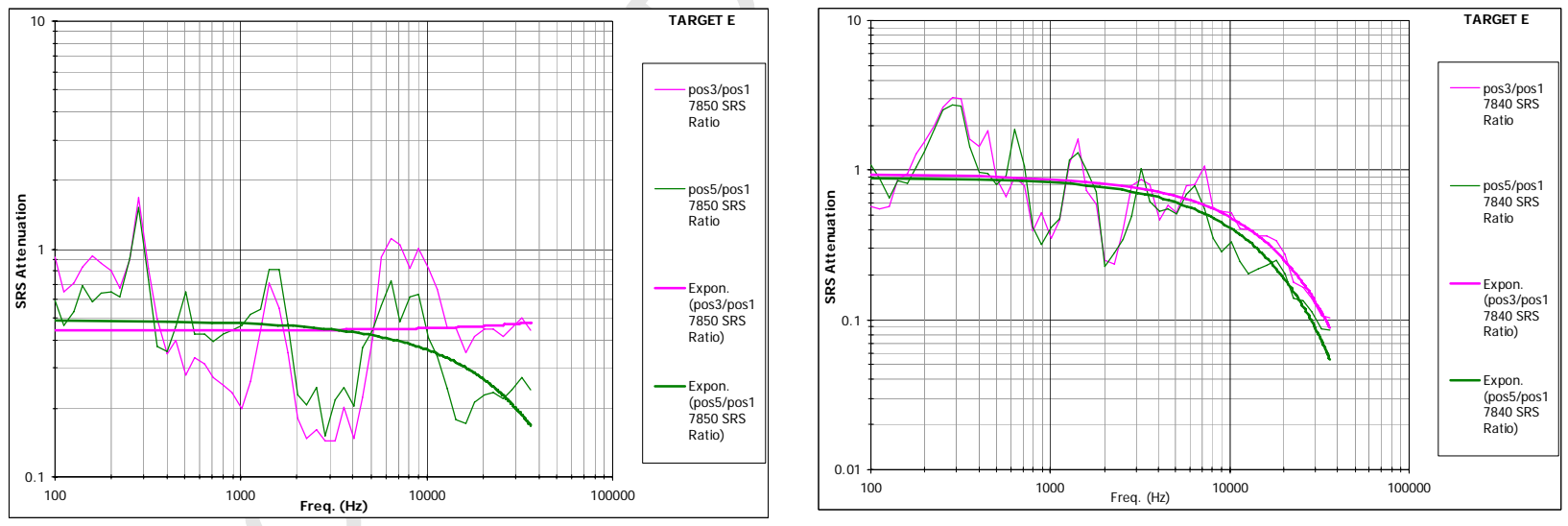

Fig. 8 pos3/pos1 and pos5/pos1 attenuation functions for shot 7850 (P) on the left and 7840 (NP) on the right

The SRS attenuation functions named "pos3/pos1" and "pos5/pos1" are plotted in Fig. 8, while the SRS attenuation functions named "pos2/pos1" and "pos4/pos1" are plotted in Fig. 9 In addition the exponential trend-lines associated to the SRS attenuation functions are also plotted to represent, in a more useful form, the attenuation effects. The following observations can be outlined from the analysis 
of the computed SRS attenuation functions:
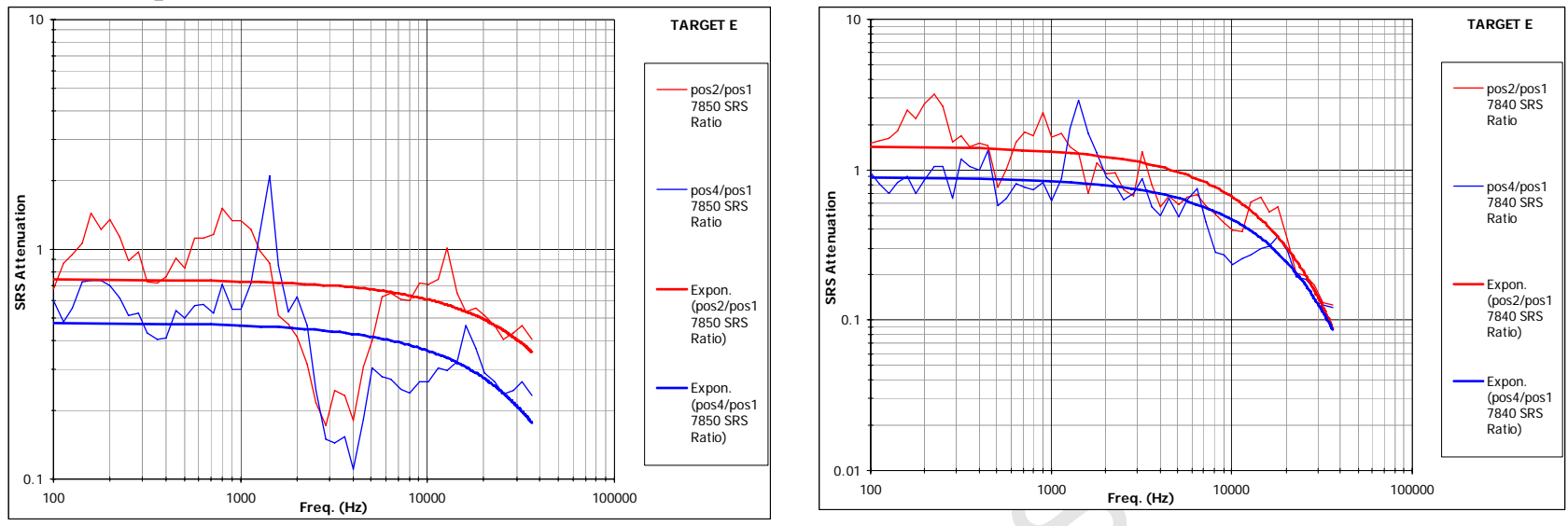

Fig. 9 pos2/pos1 and pos4/pos1 attenuation functions for shot 7850 (P) on the left and 7840 (NP) on the right

pos5/pos1 and pos3/pos1 attenuation functions

- No significant differences have been found for the two-junctions attenuation (“pos5/pos1" SRS ratio) with respect to the one-junction attenuation (“pos3/pos1" SRS ratio).

- In the low frequency range (i.e. from $100 \mathrm{~Hz}$ to about $3000 \mathrm{~Hz}$ ) the exponential trend-lines associated to the SRS attenuation functions are constant over the frequency range.

- In the high frequency range (i.e. above $3000 \mathrm{~Hz}$ ) the exponential trend-lines associated to the SRS attenuation functions are decreasing with the frequency.

The corresponding attenuation plateau values are:

- From 0.5 to 0.2 for the shots with penetration

- From 0.95 to 0.65 for the shots without penetration

pos4/pos1 and pos2/pos1 attenuation functions

- Reduction of about $30-40 \%$ has been found from the near location ("pos2/pos1” SRS ratio) to the far location ("pos4/pos1" SRS ratio).

- In the low frequency range (i.e. from $100 \mathrm{~Hz}$ to about $3000 \mathrm{~Hz}$ ) the exponential trend-lines associated to the SRS attenuation functions are constant over the frequency range.

- In the high frequency range (i.e. above $3000 \mathrm{~Hz}$ ) the exponential trend-lines associated to the SRS attenuation functions are decreasing with the frequency.

The corresponding attenuation plateau values are:

- From 0.25 to 0.75 for the shots with penetration

- From 0.65 to 1.5 for the shots without penetration

\section{Conclusions}

This paper presented an overview of the test campaign conducted on complex target in the frame of the study "Spacecraft disturbances from hypervelocity impacts", performed by CISAS and ThalesAlenia-Space under ESA contract. The goal of the activity was to investigate experimentally the transitory vibration environment produced on satellites as a consequence of hypervelocity impacts on 
their external shell. In particular, the GOCE spacecraft was selected as reference case, because of its payload, which is a very sensitive gradiometer. The research work presented in this paper was conceived to investigate the shock generation phenomena on simplified targets and then to study the propagation/attenuation effects on complex assemblies representative of real GOCE jointed configurations. The experimental range included aluminium projectiles having diameter between 0.8 and $2.3 \mathrm{~mm}$, launched at speed from 2 to $5 \mathrm{~km} / \mathrm{s}$. Main results revealed the extremely high frequency content of HVI-induced disturbances, which is largely greater than several hundreds $\mathrm{kHz}$ close to the impact point, with resulting acceleration levels exceeding several hundred thousands $\mathrm{ms}^{-2}$, for both outof-plane and in-plane waves. Away from the impact point, attenuation features for aluminium and CFRP sandwich panels were derived, together with the junction's behaviour, which appeared to be twofold: joints can act as mechanical filters or as resonators for different wave types, depending on their geometrical configuration. In particular, both loss and amplification factors obtained from HVI tests were found to be larger than the values usually employed in the standard pyroshock testing practice. Details on this point will be fundamental to tune numerical models for vibration environment calculations using numerical tools and even to upgrade the current data available on the high frequency behaviour of space structural components.

\section{Acknowledgments}

Authors wish to thank Mr. Gabriele Masiero and Mr. Luca Tasinato for the extraordinary support given in preparing and executing the impact experiments, and to Mr. Antonio Selmo for the development of the all electronic equipment.

\section{References}

[1] CNES Activity Report, 19th IADC Meeting, DLR, March 22-23, 2001 Cologne-Porz, Germany.

[2] Pavarin D, Francesconi A, Debei S, Caporal G. Preliminary design of a test bed to evaluate the requirements of an accelerometric instrumentation to study the effects of hypervelocity impacts on space shield, Mechanical Measurements Conference, 17-19 Sept. 2002, Abano Terme, Italy.

[3] Prosser WH. Application of Advanced, Waveform Based AE Techniques for testing Composite Material, Proceeding of the SPIE Conference on Nondestructive Evaluation Technique for Aging Infrastructure and manufacturing: Material and Composites, December 2-5, 1996, Scottsdale, Arizona.

[4] Prosser WH, Gorman MR, Humes H. Acoustic emission signal in thin plates produced by impact damage, Journal of Acoustic Emission, 1999; 17(1-2): 29-36.

[5] Pyroshock Test Criteria, NASA-STD-7003, 1999.

[6] Faraud M. Meteoroids and Debris Environment Analysis for Disturbance Assessment on the Gradiometer GO-TN-AI-0092, Issue 01, 30 July 2002.

[7] Faraud M. Disturbances induced by MMOD impacts GO-TN-AI-0099, Issue 01, 20 May 2003.

[8] Dynamic environmental criteria, NASA-HDBK-7005 13 March 2001.

[9] ESABASE/DEBRIS Release 2, Technical Description, S-50/95-TD-HTS, ESTEC CONTRACT 11540/95/ NL/JG, August 1998

[10] Rubin S. Concepts in Shock Data Analysis, in Shock and Vibration Handbook, 4th ed., Harris CM, ed. McGraw-Hill, NY, 1996.

[11] Trubert M, Salama MA. Generalized Modal Shock Spectra Method for Spacecraft Loads Analysis, AIAA J., 1980; 18(8): 988-994. 


\section{Pavarin, et al / International Journal of Impact Engineering}

[12] Johnson N, Christiansen E. NASA/JSC Orbital debris models, Proceedings of the Second European Conference on space debris, ESOC, Darmstadt, Germany, March 1997. 